\title{
Infective endocarditis: clinical spectrum, presentation and outcome. An analysis of 212 cases 1980-1995
}

\author{
R O-M Netzer, E Zollinger, C Seiler, A Cerny
}

\begin{abstract}
Objective-To evaluate recent changes in the spectrum and clinical presentation of infective endocarditis and to determine predictors of outcome.

Design-A retrospective case study.

Methods-Demographic, clinical, and echocardiographic characteristics were examined in 212 patients who fulfilled the Duke criteria for infective endocarditis between January 1980 and December 1995 to assess changes in clinical presentation and survival.

Results-Clinical presentation and course did not change significantly during the study period despite the concurrent introduction of new diagnostic tools (for example, transoesophageal echocardiography). In-hospital mortality was $15 \%$ and remained unchanged. Neurological symptoms on admission, arthralgia, and weight loss were all independent risk factors for adverse outcome (odds ratios 26.1, 6.2, and 4.2, respectively). Age, prosthetic valve disease, previous antibiotic treatment, renal insufficiency, surgical treatment, and the type of valve involved were not predictive of mortality. In contrast to all other major reports, Streptococcus viridans was the most common causative organism in intravenous drug users (52\%).

Conclusions-Despite the introduction of new diagnostic tools, the course of infective endocarditis has remained unchanged over a period of 16 years. Evidence of early dissemination of the disease to other sites was associated with adverse outcome. Even in elderly patients, early aggressive treatment seems to be effective.

(Heart 2000;84:25-30)
\end{abstract}

Keywords: infective endocarditis; outcome; prognostic factors

More than a century after Osler's first comprehensive description of "malignant endocarditis," and more than half a century after the discovery of sulphonamides and penicillin, ${ }^{23}$ the prognosis of infective endocarditis has changed substantially and the disease is no longer universally fatal. ${ }^{145}$ However, the annual incidence (10-20 cases/million $)^{6-9}$ and the morbidity and mortality are still relatively high. In-hospital mortality from infective endocarditis is currently reported to be between $16 \%$ and $27 \%,{ }^{10}$ while it was $40-60 \%$ in the $1950 \mathrm{~s},{ }^{411}$ and more than $30 \%$ in the 1970 s and 1980 s. $^{811}$

The persisting and substantial risk associated with infective endocarditis may reflect a continuing lack of pathognomonic diagnostic criteria, a change in the microbial spectrum, or differences in the characteristics of the affected hosts. The introduction of new diagnostic tools such as the more accurate Duke and Beth Israel criteria for infective endocarditis, ${ }^{12}{ }^{13}$ and the use of transthoracic and, more recently, transoesophageal echocardiography, may have influenced the outcome of the disease. In order to determine the impact of these and other variables on the outcome of the disease, it is essential to study large numbers of patients-a condition fulfilled in only a few recent investigations. $^{13-15}$

The purpose of this retrospective investigation among 212 patients fulfilling the Duke criteria for infective endocarditis was to assess the changing pattern of the disease during the last 16 years, to describe the clinical presenta- tion, and to determine risk factors for adverse outcome during hospital admission in a European population.

\section{Methods}

STUDY DESIGN

In a systematic retrospective review of clinical records, we analysed data on all patients admitted to hospital for infective endocarditis between 1 January 1980 and 31 December 1995 at the University Hospital Berne, Switzerland (a 1050 bed tertiary referral centre for a population of 1.2 million).

Patients with infective endocarditis were identified using the hospital database and also by a systematic review of all reports from the echocardiography laboratory between 1980 and 1995.

Of 392 patients identified, 212 fulfilled the Duke criteria for infective endocarditis ("definite" or "possible") and were included in the study; these criteria are based on pathological, clinical, and echocardiographic findings. ${ }^{13}$ Vegetations were defined as localised masses of dense shaggy echoes that were attached to a valvar leaflet or to a supporting valvar structure. Definitions of abscesses and valve perforations were circumscribed intramyocardial areas with diminished echoes, and penetrating valvar, paravalvar, or myocardial lesions visualised by colour flow Doppler mapping, respectively. Renal insufficiency was defined by a serum creatinine concentration of $>110$ $\mu \mathrm{mol} / 1$. 
Table 1 Risk factors for infective endocarditis and underlying conditions

\begin{tabular}{llll}
\hline Risk factors and underlying conditions & $\begin{array}{l}\text { Period 1980-1987 } \\
(87 \text { episodes), } n(\%)\end{array}$ & $\begin{array}{l}\text { Period 1988-1995 } \\
(125 \text { episodes), } n(\%)\end{array}$ & $p$ Value \\
\hline $\begin{array}{l}\text { Cardiac and/or non-cardiac risk } \\
\text { factors and conditions }\end{array}$ & $66(76)$ & $107(86)$ & 0.07 \\
$\begin{array}{l}\text { Cardiac risk factors } \\
\text { Pre-existing valvar heart disease }\end{array}$ & $51(59)$ & $82(66)$ & $\mathrm{NS}$ \\
Congenital heart disease & $4(5)$ & $58(46)$ & $\mathrm{NS}$ \\
Artificial heart valve & $15(17)$ & $4(3)$ & $\mathrm{NS}$ \\
Non-cardiac risk factors and & $31(36)$ & $21(17)$ & $\mathrm{NS}$ \\
$\quad$ conditions & $6(7)$ & $54(43)$ & $\mathrm{NS}$ \\
Intravenous drug use & $2(2)$ & $16(13)$ & 0.17 \\
HIV & $14(16)$ & $8(6)$ & 0.17 \\
Renal insufficiency & $11(13)$ & $23(18)$ & $\mathrm{NS}$ \\
Diabetes mellitus & 0 & $16(13)$ & $\mathrm{NS}$ \\
Pregnancy & $7(8)$ & $1(1)$ & $\mathrm{NS}$ \\
Cancer & & $15(12)$ & $\mathrm{NS}$ \\
\hline
\end{tabular}

DATA ANALYSIS

The following variables were compared during two follow up periods (1980-1987 and 19881995): demographic and clinical indices (risk factors for infective endocarditis, symptoms and signs of infective endocarditis, affected valves, and causative organisms), and outcome variables (death, cerebral deficit, valve surgery).

STATISTICAL ANALYSIS

Statistical analysis for the comparison of data between the two study periods was performed by $\chi^{2}$ test for categorical variables and the unpaired Student $t$ test for continuous variables. Univariate and multivariate analysis (Cox regression analysis) of factors predicting a fatal outcome were performed (software: StatView 4.5 by Abacus Concepts, Berkeley, California, USA). Significance was defined as a probability value of $p<0.05$. Data are shown as mean (SD).

\section{Results}

GENERAL CHARACTERISTICS OF PATIENTS

The prevalence of infective endocarditis was 0.5/1000 hospital admissions (95\% confidence interval (CI) 0.2 to 0.8 ) and did not change significantly between 1980 and 1995 (19801987, 87 episodes; 1988-1995, 125 episodes). Sex distribution ( $72 \% v 78 \%$ male), age (mean (SD) 51 (18) v 53 (18) years), duration of hospital admission (39 (22) v 35 (26) days), and mortality ( $16 \%$ v 14\% deaths) were similar during the two periods investigated.

Of 212 episodes of infective endocarditis, 155 occurred in patients with native valves (native valve endocarditis), 19 were diagnosed early (early prosthetic valve endocarditis-that is, less than 120 days), and 17 occurred late after valve replacement (late prosthetic valve endocarditis, including one intravenous drug user). Twenty one patients with native valves were known intravenous drug users. Mean duration of hospital admission did not differ significantly between these subgroups.

Infective endocarditis was suspected in $27 \%$ and its diagnosis established in $22 \%$ before admission. There was no significant difference in referral delay in the two periods studied. In $28 \%$ the working diagnosis was fever or sepsis of unknown origin. The mean interval between a previous episode of infective endocarditis and recurrence in nine patients was 157 (156) days (range 17 to 343 days).

RISK FACTORS AND UNDERLYING CONDITIONS FOR INFECTIVE ENDOCARDITIS

The spectrum of risk factors and underlying conditions did not change significantly over the study period (table 1). Cardiac risk factors were more frequent in men than in women $(67 \%$ v 50\%, p < 0.03). Rheumatic heart disease and mitral valve prolapse were each found in only $5 \%$ of the cases. Aortic (19\%) and mitral regurgitation (18\%) as well as aortic stenosis $(13 \%)$ were the most common preexisting valvar abnormalities.

The time interval between previous open heart surgery for any reason (valve replacements in 36, other reasons in four) and the development of infective endocarditis was significantly shorter during the first $(n=17)$ than during the second observation period $(\mathrm{n}=23) \quad(107 \quad$ (199) v $356 \quad$ (298) days, $\mathrm{p}<0.01)$.

Predisposing factors for bacteraemia within 120 days of admission to hospital were found in $42 \%$ of all patients ( $49 \% v 31 \%$ during the first and second periods, respectively, $\mathrm{p}<0.01)$. The most common conditions were orthodontic (19\%; mainly dental procedures or poor oral hygiene), infections or injuries of the musculoskeletal system (11\%), and vascular manipulations $(11 \% ; 10 \%$ in drug users and $1 \%$ in patients with therapeutic vascular catheterisation). The urogenital and gastrointestinal systems were possible entry sites in fewer than $3 \%$.

\section{SYMPTOMS, SIGNS, AND INITIAL LABORATORY}

ABNORMALITIES

The clinical presentation did not differ significantly between the two periods. All symptoms and signs were non-specific and occurred in a significant number of patients: fever (94\%), malaise $(81 \%)$, fatigue $(66 \%)$, loss of appetite $(52 \%)$, dyspnoea $(50 \%)$, cough $(45 \%)$, sweating $(37 \%)$, chills $(37 \%)$, weight loss $(35 \%)$, myalgia/arthralgia $(25 \%)$, back pain $(9 \%)$, vascular phenomena (53\%), and splenomegaly $(31 \%)$. On average, patients developed 6.3 (2.1) symptoms and 2.7 (1.2) signs of infective endocarditis. Cardiac symptoms or signs (that is, new or altered cardiac murmur, heart failure) were recorded in half the patients. In $36 \%$ of the episodes, neurological signs were present. They were more common in patients over 55 years of age $(43 \%$ v $30 \%$, respectively, $\mathrm{p}<0.05)$. Intracranial haemorrhages occurred in $2 \%$. Splenomegaly was found less often in patients over 55 years of age than in younger patients $(21 \% \quad v 41 \%, \mathrm{p}<0.002)$. Most patients developed haematuria $(79 \%)$ or anaemia $(91 \%)$. Patients with anaemia were more prone to malaise $(84 \%$ v $55 \%, \mathrm{p}<0.002)$ and loss of appetite $(54 \% v 30 \%, \mathrm{p}<0.04)$. Anaemia occurred more often in patients with vegetations $(94 \% \quad v 84 \%, p<0.03)$. Serum creatinine concentration was raised in $39 \%$ and $\mathrm{C}$ reactive protein in all of the 84 patients in whom it was measured on admission (mean (SD), 110 (76) $\mathrm{mg} / \mathrm{l})$. 
Valves affected 1980 to 1987

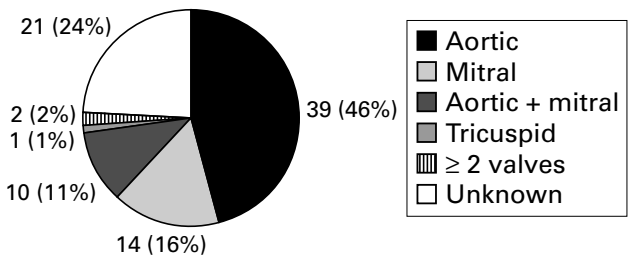

Valves affected 1988 to 1995

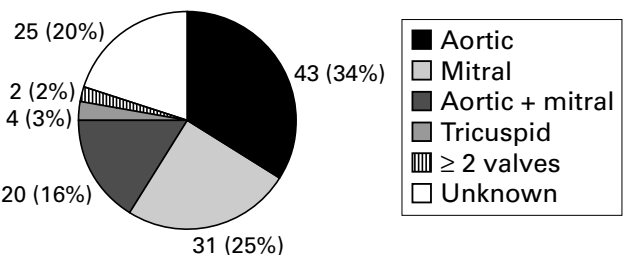

Figure 1 Valves affected.

CARDIAC CHANGES

One hundred and ninety patients underwent transthoracic echocardiography by cross sectional, $M$ mode, and colour flow Doppler mapping. Biplane or multiplane transoesophageal echocardiography was performed in 53 patients. Vegetations were diagnosed less often during the first than during the second period (60\% v 73\%, $\mathrm{p}=0.046)$, whereas there was no change in frequency of valve perforations $(30 \%$ each) or abscesses (22\% v 20\%). Vegetations and valve perforations were diagnosed more commonly in patients without prosthetic valves $(72 \%$ v $47 \%, \mathrm{p}<0.005$, and $35 \%$ v $6 \%$, $\mathrm{p}=0.0005$, respectively).

In both periods, the aortic valve, alone or in combination with other valves, was affected in more than half the cases (fig 1). The tricuspid valve was involved in eight cases and the pulmonary valve in only one patient (together with the aortic valve). There was no significant change in the frequency of infective endocarditis of the different valves in the two periods studied.

Multiple valve involvement was more common in intravenous drug users than in non-addicts $(42 \% v 18 \%, \mathrm{p}<0.03)$. Isolated left sided infective endocarditis was present in $58 \%$ of intravenous drug users. In $18 \%$ of these patients the tricuspid valve was involved, and in $24 \%$ the site of infection was unknown. Right sided infective endocarditis was never diagnosed in patients with prosthetic valves; in these patients - as well as in intravenous drug users-isolated infection of the mitral valve was relatively uncommon (intravenous drug users and early prosthetic valve endocarditis 5\% each, late prosthetic valve endocarditis $12 \%$, native valve endocarditis $26 \%$ ). Involvement of the mitral valve was more common in patients over 55 years of age than in younger patients; in the latter, infective endocarditis of the aortic and tricuspid valve was more common $(\mathrm{p}<0.02)$.
Causal organisms 1980 to 1987

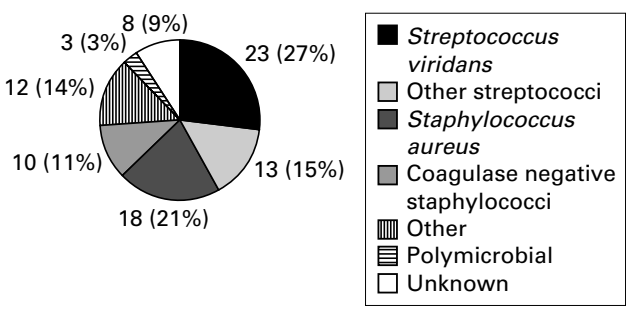

Causal organisms 1988 to 1995

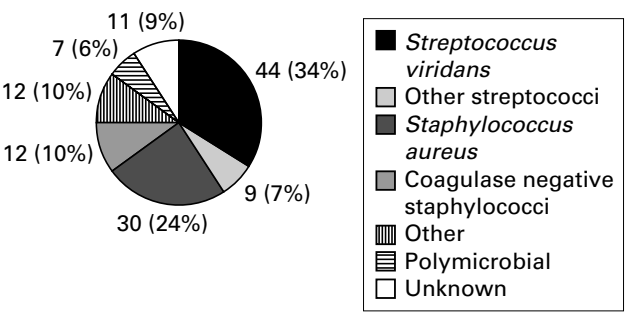

Figure 2 Causalorganisms/microbiology.

ORGANISMS RESPONSIBLE FOR INFECTIVE ENDOCARDITIS

Overall, 11 (7) blood cultures were taken in each patient. More were taken between 1988 and 1995 than during the first period: 12 (9) $v$ 10 (5) per patient, $\mathrm{p}<0.03$. A causative organism was grown in 7 (4) cultures per patient. In five of 45 cases, serological tests identified the causative organism.

Streptococci and staphylococci were isolated in about $80 \%$ of episodes in both periods (fig $2)$. Other organisms were rare: Gram negative bacteria ( $\mathrm{n}=4$ ), HACEK (Haemophilus influenzae and Haemophilus parainfluenzae, $\mathrm{n}=1$ each), miscellaneous organisms (Actinobacillus actinomyces, Bacillus species, Bacteroides uniformis, Corynebacterium pseudodiphtheriae, Propionibacterium acnes, Coxiella burnetii, Chlamydia species, $\mathrm{n}=1$ each), and polymicrobial (5\%, including four cases involving Candida species).

Surprisingly, Streptococcus viridans was the most common organism found in intravenous drug users $(52 \%)$. In patients with prosthetic heart valves, the most common organisms were coagulase negative staphylococci early (53\%) and Staphylococcus aureus (36\%) late after valve replacement. There was no significant change in the frequency of causative microorganisms between the two periods except for a decline in streptococci, other than $S$ viridans $(\mathrm{p}<0.03)$.

\section{END POINTS}

During the two periods the proportion of patients reaching the end points of death, cerebral deficit at discharge, or valve surgery did not change significantly (table 2). Death occurred in 32 patients after a mean of 22 (17) days (range 0 to 57) after admission. Mortality was highest in late prosthetic valve endocarditis (24\%) and early prosthetic valve endocarditis $(21 \%)$, and relatively low in native valves $(14 \%)$ and in intravenous drug users (10\%). 
Table 2 End points

\begin{tabular}{llll}
\hline End points & $\begin{array}{l}\text { Period 1980-1987 } \\
\text { (87 episodes), } n(\%)\end{array}$ & $\begin{array}{l}\text { Period 1988-1995 } \\
(125 \text { episodes), } n(\%)\end{array}$ & $p$ Value \\
\hline Death total & $14(16)$ & $18(14)$ & $\mathrm{NS}$ \\
$\quad$ Infective endocarditis associated & $13(15)$ & $17(14)$ & $\mathrm{NS}$ \\
Cerebral deficit & $6(8)$ & $9(8)$ & $\mathrm{NS}$ \\
$\quad$ Intracranial haemorrhages & $1(1)$ & $3(2)$ & $\mathrm{NS}$ \\
Valve surgery & $36(41)$ & $45(36)$ & $\mathrm{NS}$ \\
Mitral valve & $2(2)$ & $10(8) \dagger$ & 0.08 \\
Aortic valve & $32(37)$ & $26(21) \ddagger$ & $\mathrm{NS}$ \\
Tricuspid valve & 0 & $1(1)$ & 0.02 \\
Mitral + aortic valve & $2(2)$ & $8(6)$ & 0.17 \\
\hline
\end{tabular}

*In two additional patients, thrombectomy of the leg and resection of a mycotic aneurysm of the leg, respectively, were performed

†In two patients, reconstruction of the valve without replacement was done.

$\ddagger$ In one patient, paravalvar leakage of an artificial valve was sutured.

Table 3 Factors associated with mortality: univariate analysis

\begin{tabular}{llll}
\hline Factors & No death & Death & p Value \\
\hline Total number of events & $180(85)$ & $32(15)$ & \\
Male sex & $136(76)$ & $24(75)$ & NS \\
Mean (SD) age (years) & $51(18)$ & $61(16)$ & 0.005 \\
Cardiac risk factor(s) & $116(64)$ & $17(53)$ & NS \\
Non-cardiac risk factor(s) and underlying & $66(37)$ & $19(59)$ & $<0.02$ \\
$\quad$ conditions & & & \\
$\quad$ Intravenous drug use & $20(11)$ & $2(6)$ & NS \\
$\quad$ Pre-existing renal insufficiency & $26(14)$ & $11(34)$ & $<0.007$ \\
Mean (SD) number of symptoms on & $5(2)$ & $4(2)$ & $<0.03$ \\
$\quad$ admission & & & \\
Neurological signs on admission & $34(19)$ & $15(47)$ & 0.0005 \\
Neurological signs during IE & $55(31)$ & $22(69)$ & $<0.0001$ \\
Congestive heart failure during IE & $69(38)$ & $19(59)$ & $<0.03$ \\
Weight loss during IE & $68(38)$ & $8(25)$ & $<0.04$ \\
Fatigue during IE & $125(69)$ & $14(44)$ & $<0.005$ \\
Arthralgia during IE & $51(28)$ & $3(9)$ & $<0.02$ \\
Vascular phenomena during IE & $98(54)$ & $16(50)$ & $\mathrm{NS}$ \\
Valve perforation & $52(29)$ & $11(34)$ & $\mathrm{NS}$ \\
Vegetation & $120(67)$ & $23(72)$ & $\mathrm{NS}$ \\
Abscess in echocardiography & $10 / 171(6)$ & $6 / 22(27)$ & 0.0006 \\
Anticoagulation $\star$ & $99(55)$ & $16(50)$ & $\mathrm{NS}$ \\
Anaemia during IE & $164(91)$ & $28(88)$ & $\mathrm{NS}$ \\
Mean (SD) C reactive protein (mg/l) & $99(63)$ & $177(108)$ & 0.0007 \\
& & & \\
\hline Vales are (\%) & & & \\
\end{tabular}

Values are $\mathrm{n}(\%)$ unless otherwise specified.

${ }^{\star}$ Started within 30 days of initiation of antibiotic treatment.

IE, infective endocarditis, NS, not significant.

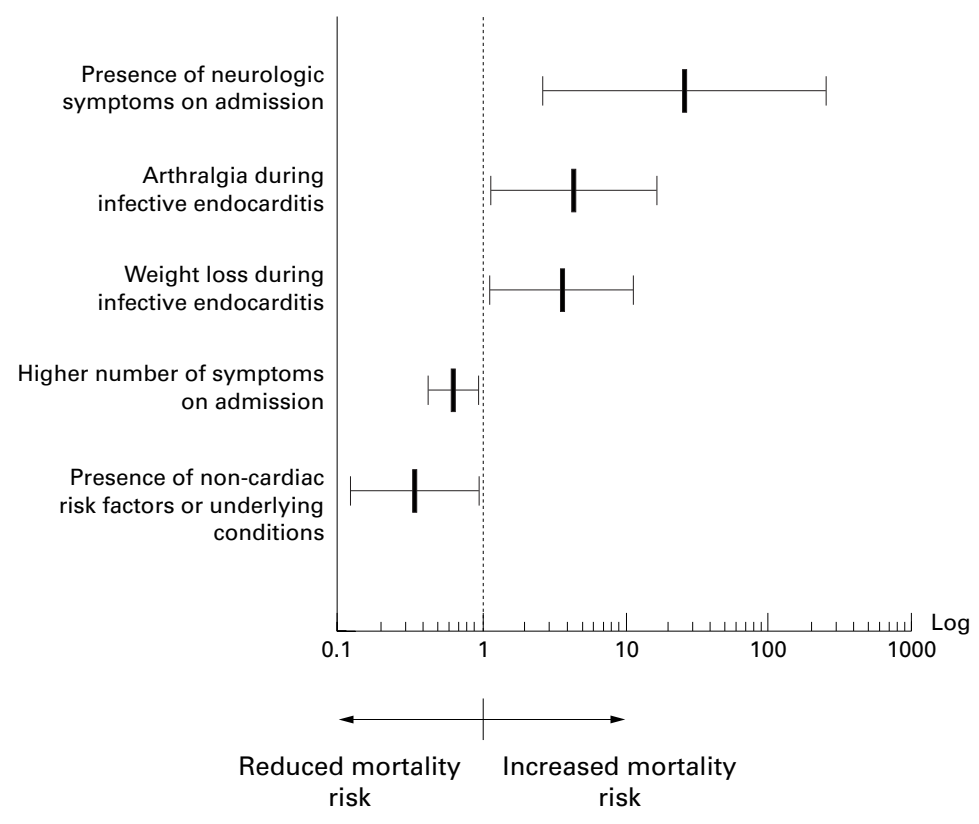

Figure 3 Risk factors for mortality

Necropsy, which was performed in 21 patients, revealed vegetations, perforation, and abscesses in 15, five, and four patients, respectively. Dehiscence at the attachment of the prosthetic valve was present in two patients with late prosthetic valve endocarditis and in one patient with early prosthetic valve endocarditis.

Cerebral deficit was most common in early prosthetic valve endocarditis (three of 13 patients). Of the 77 patients who were transferred to other institutions for further medical care, the duration of the subsequent hospital stay was significantly longer in patients with a neurological deficit than in the remainder (85 (63) v 29 (17) days). In these cases the number of positive blood cultures during antibiotic treatment was higher, at 4 (3) $v 2$ (2) blood cultures per patient $(\mathrm{p}<0.002)$, and vegetations were diagnosed more often $(94 \% v$ $64 \%, \mathrm{p}<0.03)$.

Although the frequency of surgical treatment of infective endocarditis did not change during the 16 years studied, there was a decline in isolated aortic valve replacement $(\mathrm{p}<0.02)$, and a trend towards more frequent surgery of the mitral valve, both alone and in combination with the aortic valve. More than half the patients with prosthetic valves (early prosthetic valve endocarditis and late prosthetic valve endocarditis, 53\% each) required valve replacement, while valve surgery was performed in $29 \%$ of intravenous drug users and in $38 \%$ of cases of native valve endocarditis.

FACTORS ASSOCIATED WITH MORTALITY

Several demographic and clinical factors showed an association with fatal outcome in univariate analysis (table 3). Although, overall, infective endocarditis caused by staphylococci was no more likely to be fatal than that caused by streptococci, mortality was higher with $S$ aureus than with $S$ viridans $(19 \%$ v $6 \%$, $\mathrm{p}<0.03)$. $S$ viridans caused fewer fatalities than all the other organisms combined $(6 \% v$ $19 \%, \mathrm{p}<0.02)$. There was a trend towards lower mortality in patients who had undergone valve surgery $(10 \% v 19 \%, \mathrm{p}=0.08)$.

In multivariate analysis, the presence of neurological signs on admission was the strongest predictor of in-hospital mortality (fig 3). However, risk was also increased for patients with arthralgia and weight loss. In contrast, a larger number of symptoms on admission and the presence of non-cardiac risk factors for infective endocarditis were both associated with a reduced mortality risk.

\section{Discussion}

This retrospective evaluation in 212 patients shows an unaltered mode of presentation and clinical course of infective endocarditis during two eight year study periods (starting in 1980), despite the concurrent introduction of new diagnostic tools (for example, transoesophageal echocardiography). However, a consistently low mortality rate was found in comparison with other published data, and the study population was large enough to identify various risk indicators for a fatal outcome.

There are reports suggesting that there have been changes in the presentation of infective endocarditis over recent decades, particularly in the age of patients, the risk factors for establishment of endocarditis, and the causative organisms. ${ }^{516}$ In spite of emergence of 
intravenous drug use as an increasingly important risk factor for infective endocarditis, the mean age of our patients (53 years) has tended to increase during the two periods investigated; this reflects the ongoing trend towards increasing age at presentation of infective endocarditis during this century, ${ }^{17-20}$ and is consistent with other reports (mean 46-64 years). ${ }^{811} 14152122$

As in other studies, ${ }^{162324}$ in our series the diagnosis of infective endocarditis was made relatively late in the course of the disease, and this feature has not been changed by the introduction of new diagnostic tools, such as transoesophageal echocardiography in 1987 or new diagnostic criteria in 1981 (Beth Israel) ${ }^{12}$ and 1994 (Duke) $^{13}$. It is likely to reflect the persistent diagnostic dilemma of a disease that has few pathognomonic clinical or laboratory features.

Mitral valve prolapse, which has been described as an important predisposing factor in several reports, ${ }^{11} 2122{ }^{25-27}$ was relatively rare in our population. The overall prevalence of cardiac risk factors (63\%) was comparable with that in other series (42-85\%). ${ }^{8} 12152128-30$

$S$ viridans, which increased in frequency between 1980-1987 and 1988-1995, in contrast to other reports, ${ }^{16}{ }^{22}$ remained the principal pathogen, followed by $S$ aureus, which was more prevalent in the second period. Surprisingly, this was also true for intravenous drug users, more than half of whom were infected with $S$ viridans. All other major series ${ }^{514} 1521$ have reported that $S$ aureus is the most frequent causative organism. The low recovery rate of $S$ aureus in drug addicts in our population might be a reflection of improved injection hygiene associated with the distribution of sterile injection material in a nationwide programme introduced in 1986. Attention to oral hygiene in health care programmes might further reduce the incidence of infective endocarditis in these individuals by focusing on the possible risk of streptococcal bacteraemia.

\section{MORTALITY}

There was a tendency towards declining mortality during the two periods investigated. Compared with other larger series $\left(16-33 \%^{8152122}\right.$ ), mortality was relatively low in our population, especially in infections with $S$ aureus $\left(25-47 \%{ }^{8} 9^{11} 15^{21}\right)$.

No obvious explanation for the low mortality rate, such as differences in the populations studied, could be identified. Selection bias in our series is unlikely, although there is a theoretical possibility of more severe cases dying before admission to our tertiary care centre. On the other hand, referral of predominantly mild cases to our institution is unlikely. However, long term follow up data were not analysed.

In a recent study, Siddiq and colleagues found that congestive heart failure and renal failure were associated with increased mortality in a logistic regression model. ${ }^{14}$ The applicability of these findings is limited, as $67 \%$ of the patients they studied were intravenous drug users.
In a prospective epidemiological study from the Netherlands, the recovery of $\alpha$ haemolytic streptococci was the only independent factor for decreased mortality. ${ }^{9}$ Steckelberg and colleagues reported a trend towards higher mortality in patients aged 65 years or older in a community cohort. ${ }^{31}$ In both papers, the Beth Israel criteria were applied for diagnosis of infective endocarditis, and the study by Steckelberg dates back to the 1970 s.

In our study, many factors were associated with increased in-hospital mortality (table 3). However, variables such as prosthetic valve infective endocarditis, previous antibiotic treatment, serum creatinine concentration, surgical treatment, and valve involvement were not predictive of mortality.

In multivariate analysis, neurological symptoms on admission, arthralgia, and weight loss were strong independent predictors of increased mortality, all indicating systemic disease; the first two reflect disease progression with dissemination of infective emboli.

In contrast to other reports, ${ }^{14}{ }^{32}$ congestive heart failure during infective endocarditis was not an independent risk factor in our study. One possible explanation for this is the relatively high percentage of patients treated surgically in our series. This has been reported to improve outcome in patients with significant congestive heart failure and to prevent this complication in others if they are operated on early in the course of the disease. ${ }^{33}{ }^{34}$ However, owing to the retrospective design of the analysis, grading of congestive heart failure (for example by the New York Heart Association classification) was unreliable and was therefore not done.

Independent factors for reduced mortality risk included a larger number of symptoms on admission and the presence of non-cardiac risk factors or underlying conditions-both presumably leading the treating physician to undertake a more rapid and vigorous investigation and to start treatment of the underlying disease earlier.

\section{CONCLUSIONS}

At our centre, the presentation and course of infective endocarditis have remained remarkably stable between 1980 and 1995. The introduction of new diagnostic tools (new imaging techniques, improved culture methods) has had no impact on outcome. Our study underscores the importance of early detection of infective endocarditis before dissemination, combined with rapid and aggressive treatment of patients in all age groups.

1 Osler W. The gulstonian lectures on malignant endocarditis. BMF 1885;i:467-70, 522-6, 577-9.

2 Lichtman SS. Treatment of subacute bacterial endocarditis: current results. Ann Intern Med 1943;19:787-94.

3 Geraci JE, Martin WJ. Antibiotic therapy of bacterial endocarditis: clinical, pathologic, and therapeutic consideration of 33 cases. Circulation 1954;10:173-94.

4 Lowes JA, Hamer J, Williams G, et al. 10 Years of infective endocarditis at St. Bartholomew's Hospital: analysis of clinical features and treatment in relation to prognosis and mortality. Lancet 1980;i:133-6.

mortality. Lancet $1980 ; 1: 133-6$.
5 McCartney AC. Changing trends in infective endocarditis. $\mathcal{F}$ Clin Pathol 1992;45:945-8.

6 Young SE. Aetiology and epidemiology of infective endocarditis in England and Wales. F Antimicrob Chemother 1987;20:7-15. 
7 King JW, Nguyen VQ, Conrad SA. Results of a prospective statewide reporting system for infective endocarditis. $A m \mathcal{F}$ Med Sci 1988;295:517-27.

8 Nissen H, Nielsen PF, Frederiksen $M$, et al. Native valve infective endocarditis in the general population: a 10 -year survey of the clinical picture during the 1980s. Eur Heart $f$ 1992;13:872-7.

9 van der Meer JT, Thompson J, Valkenburg HA, et al. Epidemiology of bacterial endocarditis in The Netherlands. I. Patient characteristics. Arch Intern Med 1992;152:1863-8.

10 Karchmer AW. Infective endocarditis. In: Braunwald E, ed. Heart disease: a textbook of cardiovascular medicine, 5 th $\mathrm{ed}$ Philadelphia: WB Saunders, 1997:1077-104.

11 Griffin MR, Wilson WR, Edwards WD, et al. Infective endocarditis. Olmsted County, Minnesota, 1950 through 1981. FAMA 1985;254:1199-202.

12 Von Reyn CF, Levy BS, Arbeit RD, et al. Infective endocarditis: an analysis based on strict case definitions. Ann Intern Med 1981;94:505-18.

13 Durack DT, Lukes AS, Bright DK. New criteria for diagnosis of infective endocarditis: utilization of specific echocardiographic findings. Duke Endocarditis Service. Am $\mathcal{F} \mathrm{Med}$ 1994;96:200-9.

14 Siddiq S, Missri J, Silverman DI. Endocarditis in an urban hospital in the 1990s. Arch Intern Med 1996;156:2454-8.

5 Watanakunakorn C, Burkert T. Infective endocarditis at a large community teaching hospital, 1980-1990. A review of 210 episodes. Medicine (Baltimore) 1993;72:90-102.

16 Brandenburg RO, Giuliani ER, Wilson WR, et al. Infective endocarditis - a 25 year overview of diagnosis and therapy. 7 Am Coll Cardiol 1983;1:280-91.

17 Thayer WS. Studies on bacterial (infective) endocarditis. fohns Hopkins Hosp Rep 1926;11:1-5.

18 Kelsou SR, White PD. Notes on 250 cases of subacute bacterial (streptococcal) endocarditis studied and treated between 1927 and 1939. Ann Intern Med 1945;22:40-60.

19 Wedgwood J. Early diagnosis of subacute bacterial endocarditis. Lancet 1955; ii: $1058-63$.

20 Lerner PI, Weinstein L. Infective endocarditis in the antibiotic era. N Engl F Med 1966;274:199-206.
21 Sandre RM, Shafran SD. Infective endocarditis: review of 135 cases over 9 years. Clin Infect Dis 1996;22: 276-86

22 Schon HR, Fuchs CJ, Schomig A, et al. Changes in infectious endocarditis - analysis of a disease picture in the last decade [in German]. Z Kardiol 1994;83:31-7.

23 Lode $\mathrm{H}$, Harnoss $\mathrm{CM}$, Wagner $\mathrm{J}$, et al. Infectious endocarditis: clinical findings, therapy and course in 103 patients [in German]. Dtsch Med Wochenschr 1982;107: 967-74

24 Misteli M, Conen D. Infectious endocarditis: reasons for a delayed diagnosis [in German]. Schweiz Med Wochenschr 1991;121:826-31.

25 Bayer AS. Infective endocarditis. Clin Infect Dis 1993;17: 313-20; quiz 321-2.

26 Clemens JD, Horwitz RI, Jaffe CC, et al. A controlled evaluation of the risk of bacterial endocarditis in persons with mitral-valve prolapse. $N$ Engl f Med 1982;307:77681

27 Steckelberg JM, Wilson WR. Risk factors for infective endocarditis. Infect Dis Clin North Am 1993;7:9-19.

28 Gossius G, Gunnes P, Rasmussen K. Ten years of infective endocarditis: a clinicopathologic study. Acta Med Scand 1985;217:171-9.

29 McKinsey DS, Ratts TE, Bisno AL. Underlying cardiac lesions in adults with infective endocarditis. The changing spectrum. Am F Med 1987;82:681-8.

30 Whitby $M$, Fenech $A$. Infective endocarditis in adults in Glasgow, 1976-81. Int f Cardiol 1985;7:391-403.

31 Steckelberg JM, Melton LJd, Ilstrup DM, et al. Influence of referral bias on the apparent clinical spectrum of infective endocarditis. Am 7 Med 1990;88:582-8.

32 Woo KS, Lam YM, Kwok HT, et al. Prognostic index in prediction of mortality from infective endocarditis. Int $\mathcal{F}$ Cardiol 1989;24:47-54

33 Mills J, Utley J, Abbott J. Heart failure in infective endocarditis: predisposing factors, course, and treatment. Chest 1974;66:151-7.

34 Richardson JV, Karp RB, Kirklin JW, et al. Treatment of infective endocarditis: a 10-year comparative analysis. Circulation 1978;58:589-97.

\section{IMAGES IN CARDIOLOGY}

\section{Coronary artery calcification}

Ultrafast computed tomography (CT) of the heart of a 46 year old man who presented with atypical chest pain revealed an increased calcium score of 1226, and showed severe calcification of the left main stem (LMS), the proximal left anterior descending (LAD) and the first diagonal (D1) arteries, suggesting the presence of significant underlying atherosclerosis. Subsequent coronary angiography revealed significant stenoses of the LMS, LAD, left circumflex, and D1 arteries. The patient underwent coronary artery bypass grafting and is now symptomatically well. Calcium is a component of the atherosclerotic plaque, and measurement of total coronary calcium score by ultrafast CT is a highly sensitive indicator of underlying atherosclerotic plaque burden. Ultrafast CT may be an appropriate first investigation in patients with atypical cardiac symptoms, in whom the pretest likelihood for ischaemic disease is considered low by the clinician.

AFSHIN FARZANEH-FAR PETER L WEISSBERG RICHARD COULDEN

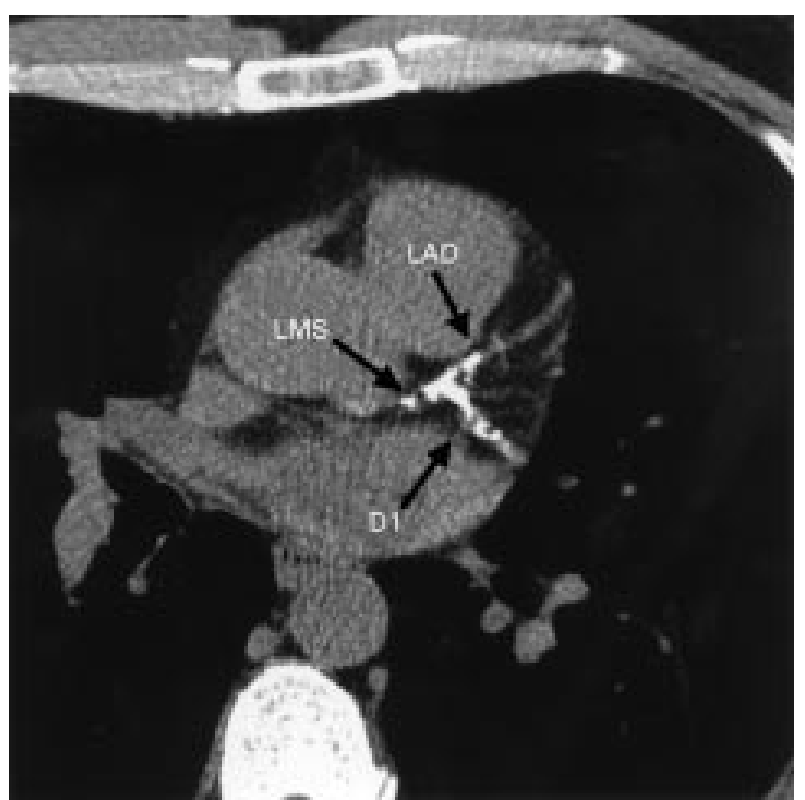

